\title{
Transfer of Fibers in a Flat Card
}

\author{
By Kazuo Ueda, Yoshihiko $\overline{0}$ goshi and Kenichi Shirai, Members, TMSJ \\ Toho Rayon Co., Ltd., Ibigawa, Gifu Pref.
}

\begin{abstract}
The rate of the transfer of fibers from a cylinder to a doffer and the quantity of fibers on a cylinder have been investigated with the use of rayon staples carded with a flat card. The purpose is to get a proper distribution of fibers on the cylinder and thus increase production on a metallic card.

Results :

(1) $P$ is constant irrespective of the fiber density on a cylinder.

(2) $P$ is $6 \sim 7 \%$ on ordinary carding cloth and $9 \%$ on metallic carding cloth.

(3) To reduce $P$, it is helpful to reduce the working angle of the doffer metallic wire.

(4) The quantity of fibers on a cylinder is about 90 grains with ordinary carding cloth, about 68 grains with metallic carding cloth in the normal running state in which slivers of 280 grains $/ 6$ yards are carded. Both values are less than the quantity of sinking fibers between the carding cloth of a cylinder and the flat.

Therefore, by increasing $P$ on a metallic card, it is possible to reduce the quantity of fibers on a cylinder and improve the efficiency of carding action.
\end{abstract}

\section{Introduction}

Metallic card clothing for use on card is replacing fillet card clothing in many mills. By using metallic clothing on about 20 cards for the rayon spinning process in the mill where the authors work, they noticed many good points about metallic clothing.

Generally metallic clothing with fewer toothpoints in a certain dimension of wire has a smaller number of tooth-points to affect fibers than fillet clothing. Likewise, our findings on the conventional fillet clothing do not always apply to metallic clothing. The data based on fillet clothing needs reexamination in respect of machine conditions (e.g., tooth-shape of metallic wire, wire density, roller settings) and maximum production if those data are to be applied to metallic clothing. Hence increased production is possible with the use of metallic cloth. ing.

To find out how many teeth of metallic clothing are in action to affect fibers on the cylinder, the usual method is to measure conventionally the fiber quantity of lap feeded. The authors suggest, instead, the measuring of the actual fiber quantity on the cylinder, because the fiber quantity on the cylinder has a considerable bearing on the efficiency of carding action.
This report describes the movement of fibers from the cylinder to the doffer and the fiber quantity on the cylinder in an effort to get theoretical formulas on experiments.

\section{Theoretical Analysis}

A fiber on a flat card moves forward to the Lickerin roller cylinder, and doffer in that order. Note that, in rayon spinning, $100 \%$ fiber moves on from the Lickerin-roller to the cylinder. It is, therefore, from the rate of fiber transfer from the cylinder to the doffer that the fiber quantity should be figured out. We make the following assumptions for analytical purposes:

1) That carding action by the top is nil. Fibers sticking to the top are assumedly excluded from fed lap. The fiber quantity of fed lap, therefore, equals the quantity of slivers produced per unit time.

2) That the fiber quantity from the cylinder to the doffer per revolution of the cylinder is proportionate to the fiber quantity on the cylinder. The rate of fiber transfer from the cylinder to the doffer will be referred to in this article as "the rate of transfer"; the remaining rate, as "the residual rate." 
(3) That the fiber quantity of fed lap is constant per unit time. The following symbols will be used (see Fig. 1):

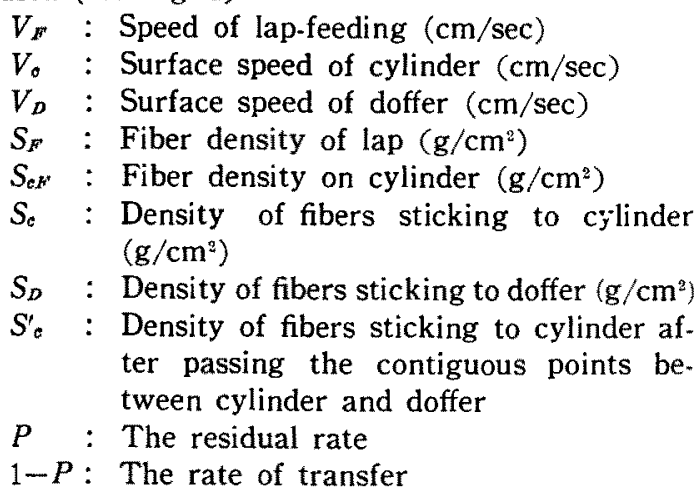

2-1. Fiber transfer under normal conditions

Fig. 2 shows two flows of fibers between the cylinder and doffer. Fibers on the cylinder are carried at a surface speed of $V_{0}$ to the contiguous points where the cylinder and doffer come closest to each other. Then part of the fibers are transferred to the doffer at a surface speed of $V_{D}$.

The amount of waste fibers dumped from the contiguous points being negligible. The following formula is obtained:

$$
S_{D} \cdot V_{D}=S_{\mathfrak{c}} \cdot V_{c}-S_{c}^{\prime} \cdot V_{c}=S_{c} \cdot V_{c}\left(1-\frac{S_{c}^{\prime}}{S_{c}}\right)
$$

where $\quad \frac{S_{c}^{\prime}}{S_{c}}=P$

Therefore, $\quad S_{D}=\frac{V_{c}}{V_{D}} S_{c}(1-P)$

In formula (2), if $P=1$, i.e., if all fibers on the cylinder remain there after passing the contiguous points, then $S_{D}=0$, which means that carding action is nil. If $P=0$, i.e., if all fibers on the cylinder move onto the doffer, then $S_{D}=\left(\frac{V_{c}}{V_{D}}\right) \cdot S_{c}$. This means an extremely low density of fibers on the cylinder.

Between these extremes with $S_{D}$ assumed to be a constant (i.e., with sliver grains assumed to be a constant), the fiber density on the cylinder increases in value as $P$ increases and $1-P$ decreases. In other words, the residual rate increases and the rate of transfer decreases. Naturally, a large amount of fibers sticking to the cylinder hinders effectual carding action, with the possible result that many neps may develop or many fibers may be broken.
The same trouble occurs when production is increased, i.e., if $S_{D}$ in formula (2) increases, without a change in the rate of transfer. Therefore, production can be increased without mishaps if the rate of transfer increases with the increase of production or if the rate of transfer increases with enough reserve of fiber quantity on the cylinder. Therefore, the larger the rate of transfer the better.

The rate of transfer may conceivably change $\frac{V_{e}}{V_{D}}$. Increasing production by increasing the surface speed $V_{D}$ of the doffer, results in a larger quantity of fibers on the cylinder unless the rate of transfer changes. It is important, then, to grasp the meaning of $\frac{V_{\varepsilon}}{V_{D}}(1-P)$. Before increasing production, it is necessary to decide whether to increase the fiber density on the doffer or the doffer surface speed, to fix properly the proportions of the load on the fiber density and the doffer surface speed avoid overloading of the cylinder with fibers.

2-2. How sliver grains decrease when lap-feeding stops

Formula (2) has established the relation between the fiber quantities on the cylinder and on the doffer when fibers are fed to the cylinder constantly. Stoppage of lap-feeding reduces the fiber density on the doffer gradually. The reduction can be ex-

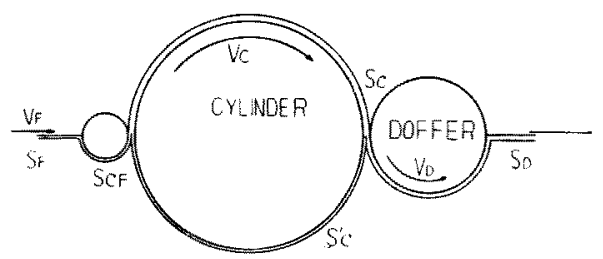

Fig. 1 Sign

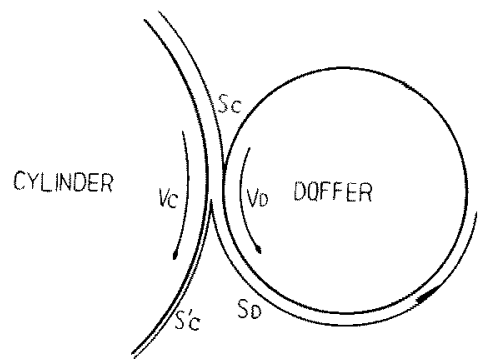

Fig. 22 flow of fiber where cylinder and doffer draw nearest 
pressed in the form of a formula by changing the fiber quantity $S_{c}$ as on the cylinder. That is to say: After one revolution of cylinder: $S_{c}(1)=S_{c} \cdot P$

After two revolutions of cylinder: $S_{e}(2)=S_{c} \cdot P^{2}$

After revolution $n$ times: $S_{c}(n)=S_{c} \cdot P^{n}$

Replace $S_{c}$ in formula (2) with $S_{c}(n)$, and we get:

$$
S_{D}(n)=\frac{V_{e}}{V_{D}} \cdot S_{c} \cdot P^{n} \cdot(1-P)
$$

2-3. How sliver grains increase with start of lapfeeding

Here we begin our analysis in the condition: $S_{\mathrm{c}}=0$, i.e., in a condition in which sliver grains nil because of the stoppage of lap-feeding. How does the fiber density on the doffer increase when lapfeeding starts again? The relation between the fiber density of fed lap and the fiber density on the cylinder is as follows:

$$
\begin{aligned}
& S_{C F^{\prime}}=S_{F^{\prime}} \cdot \frac{V_{F}}{V_{e}} \\
& S_{e}(n)=S_{c F}+S_{C F} \cdot P+S_{C F} \cdot P^{2}+\cdots \cdots+S_{c F} \cdot P^{n-2}+S_{c F} \cdot P^{n-1} \\
& =S_{c F^{N}} \frac{1-P^{n}}{1-P}
\end{aligned}
$$

Putting expression (5) into formula (2) gives us :

$$
S_{D}(n)=\frac{V_{c}}{V_{D}} S_{c F} \cdot(1-P)
$$

which shows how sliver grains increase with the start of lap-feeding.

For $n \rightarrow \infty$ in the formula (6), $1-P$ is obtained. (since $|P|<1$ )

This, in turn, leads to the following formula of draft :

$$
S_{D}=\frac{V_{c}}{V_{D}} \quad S_{c F}=\frac{V_{F}}{V_{D}} \cdot S_{F}
$$

With time, i.e., as $n$ increases, so the fiber density on the doffer approaches a certain value, which can be expressed in the expression (5) for $n \rightarrow \infty$ as:

$$
S_{c}=S_{c F} \cdot \frac{1}{1-P}=\frac{V_{c}}{V_{D}} \quad S_{D} \cdot \frac{1}{1-P}
$$

Formulas (3) and (6) assume that the rate of transfer $1-P$, is constant, irrespective of the fiber density on the cylinder. The validity depends on results of experiments. As shown in Fig. 3 for the formula (3) and in Fig. 4 for the formula (6), they present stair-like curves. In practice, however, such variations cannot be identified by measuring sliver grains. Moreover, the fiber density on the cylinder cannot be measured with sufficient precision.
Therefore, dotted lines as in Figs. 3 and 4 are substituted.

\section{Methods of Experimenting}

With the aid of formula (3) we measured the rate of derease in sliver grains when lap-feeding was stopped. The purpose was to verify the theories expounded thus far in this article and to calculate the rate of movement $1-P$ and the residual rate $P$.

With machine conditions to be clarified later on, feeding lap was stopped or started again as experiment required. Sliver grain being measured by the uster evenness tester, the values of $P$ and $1-P$ were obtained by:

$$
\log S_{D}(n)=\log \frac{V_{c}}{V_{D}} \cdot S_{c}(1-P)+n \log P
$$

where $0<|P|<1 \quad \log P<0$

$P$ was obtained from the inclination of the straight line in Fig. 5 for formula (3)'.

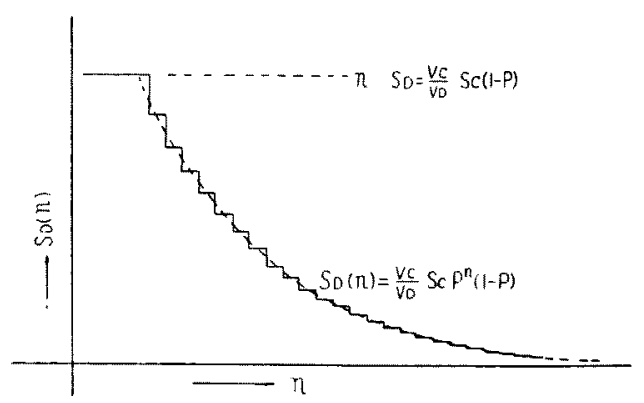

Fig. 3 Change of sliver grain decreases upon stoppage of feeding lap

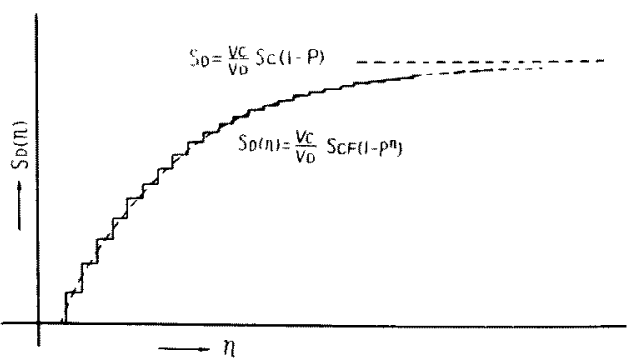

Fig. 4 Change of sliver grain increases on start of feeding lap 


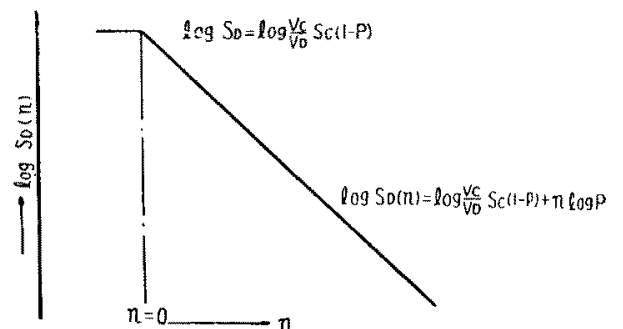

Fig. 5 Relation of $n$ and $\log S_{D}$ upon stoppage of feeding lap

Table 2 Condition of cards used experiment

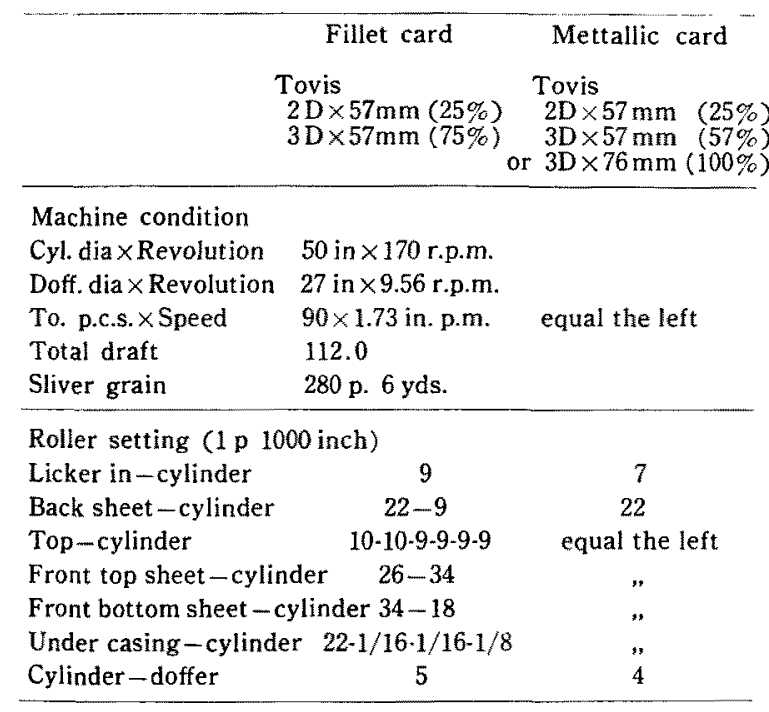

\section{Conditions of Experimenting}

Table 1 shows the details of the card clothing used in our experiment. Card machines with standard type fillet clothing gave standard value of the rate of transfer. As for metallic clothing, eight machines were used. Of the eight, four, standard type clothing; one, with extraordinarily low wire; two, with small working angle of doffer wire; one, remodelled from a flat card as roller card for spinning synthetic fiber. Table 2 shows machine conditions together with main settings.

\section{Results of Experiments Evaluated}

The charts appended to this article changes in sliver grains where lap-feeding was stopped at the left side and started in the middle. All based on standard data of each testing machine.

Generally, it is easy to measure a decrease in sliver grains and difficult to measure an increase, because it is not easy to collect samples through the calender part and also because sliver grains vary too much to be measurable. The variations, if dotted in logarithm as in Fig. 6 are of a linear type. The linearity of sliver grains of a small range is distorted by latent variations in slivers. Also, in a small range of grains, some machine produced broken web on metallic clothing.

Despite a few difficulties, the theoretical formulas expounded in this article have been found applicable

Table 1 Carding of test machine used experiment

\begin{tabular}{|c|c|c|c|c|c|c|c|c|c|c|}
\hline \multirow{2}{*}{$\begin{array}{c}\text { Test } \\
\text { machine } \\
\text { No. }\end{array}$} & \multirow{2}{*}{$\begin{array}{l}\text { Carding } \\
\text { cloth }\end{array}$} & \multicolumn{3}{|c|}{ Cylinder } & \multicolumn{3}{|c|}{ Doffer } & \multicolumn{3}{|c|}{ Top } \\
\hline & & $\begin{array}{l}\text { Wire } \\
\text { density }\end{array}$ & $\begin{array}{c}\text { Working } \\
\text { angle }\end{array}$ & Height & $\begin{array}{l}\text { Wire } \\
\text { density }\end{array}$ & $\begin{array}{l}\text { Working } \\
\text { angle }\end{array}$ & Height & $\begin{array}{l}\text { Wire } \\
\text { density }\end{array}$ & $\begin{array}{c}\text { Working } \\
\text { angle }\end{array}$ & Height \\
\hline 1 & F.C.C. & $120 \mathrm{~S}$ & $77^{\circ}$ & 10 & $120 \mathrm{~S}$ & $74^{\circ}$ & 10 & $120 \mathrm{~S}$ & $78.3^{\circ}$ & 9.0 \\
\hline 2 & F.C.C. & $110 \mathrm{~S}$ & $78^{\circ}$ & 10 & $120 \mathrm{~S}$ & $73^{\circ}$ & 10 & $120 \mathrm{~S}$ & $78.8^{\circ}$ & 9.0 \\
\hline 3 & F.C.C. & $110 \mathrm{~S}$ & $73^{\circ}$ & 10 & $120 \mathrm{~s}$ & $71^{\circ}$ & 10 & $120 \mathrm{~S}$ & $79.8^{\circ}$ & 9.0 \\
\hline 4 & M.C.C. & $84 \mathrm{~S}$ & $78^{\circ}$ & 4.2 & $84 \mathrm{~S}$ & $73^{\circ}$ & 4.2 & $120 \mathrm{~S}$ & $78.5^{\circ}$ & 9.0 \\
\hline 5 & M.C.C. & $84 \mathrm{~S}$ & $78^{\circ}$ & 4.2 & $84 \mathrm{~S}$ & $73^{\circ}$ & 4.2 & $90 \mathrm{~S}$ & $75^{\circ}$ & 9.0 \\
\hline 6 & M.C.C. & $74 \mathrm{~S}$ & $76^{\circ}$ & 4.1 & $70 \mathrm{~S}$ & $71^{\circ}$ & 4.1 & $90 \mathrm{~S}$ & $75^{\circ}$ & 8.9 \\
\hline 7 & M.C.C. & $84 \mathrm{~S}$ & $78^{\circ}$ & 4.2 & $84 \mathrm{~S}$ & $73^{\circ}$ & 4.2 & $90 \mathrm{~S}$ & $75^{\circ}$ & 8.9 \\
\hline 8 & M.C.C. & $76 \mathrm{~S}$ & $78^{\circ}$ & 4.2 & $81 \mathrm{~S}$ & $69^{\circ}$ & 4.5 & $90 \mathrm{~S}$ & $75^{\circ}$ & 9.0 \\
\hline 9 & M.C.C. & $89 \mathrm{~S}$ & $78^{\circ}$ & 3.7 & $90 \mathrm{~S}$ & $73^{\circ}$ & 3.7 & $80 \mathrm{~S}$ & $75^{\circ}$ & 9.0 \\
\hline 10 & M.C.C. & $84 \mathrm{~S}$ & $78^{\circ}$ & 4.2 & $84 \mathrm{~S}$ & $73^{\circ}$ & 4.2 & & & \\
\hline 11 & M.C.C. & & & & & $\begin{array}{l}60^{\circ} \\
50^{\circ}\end{array}$ & & & & \\
\hline
\end{tabular}




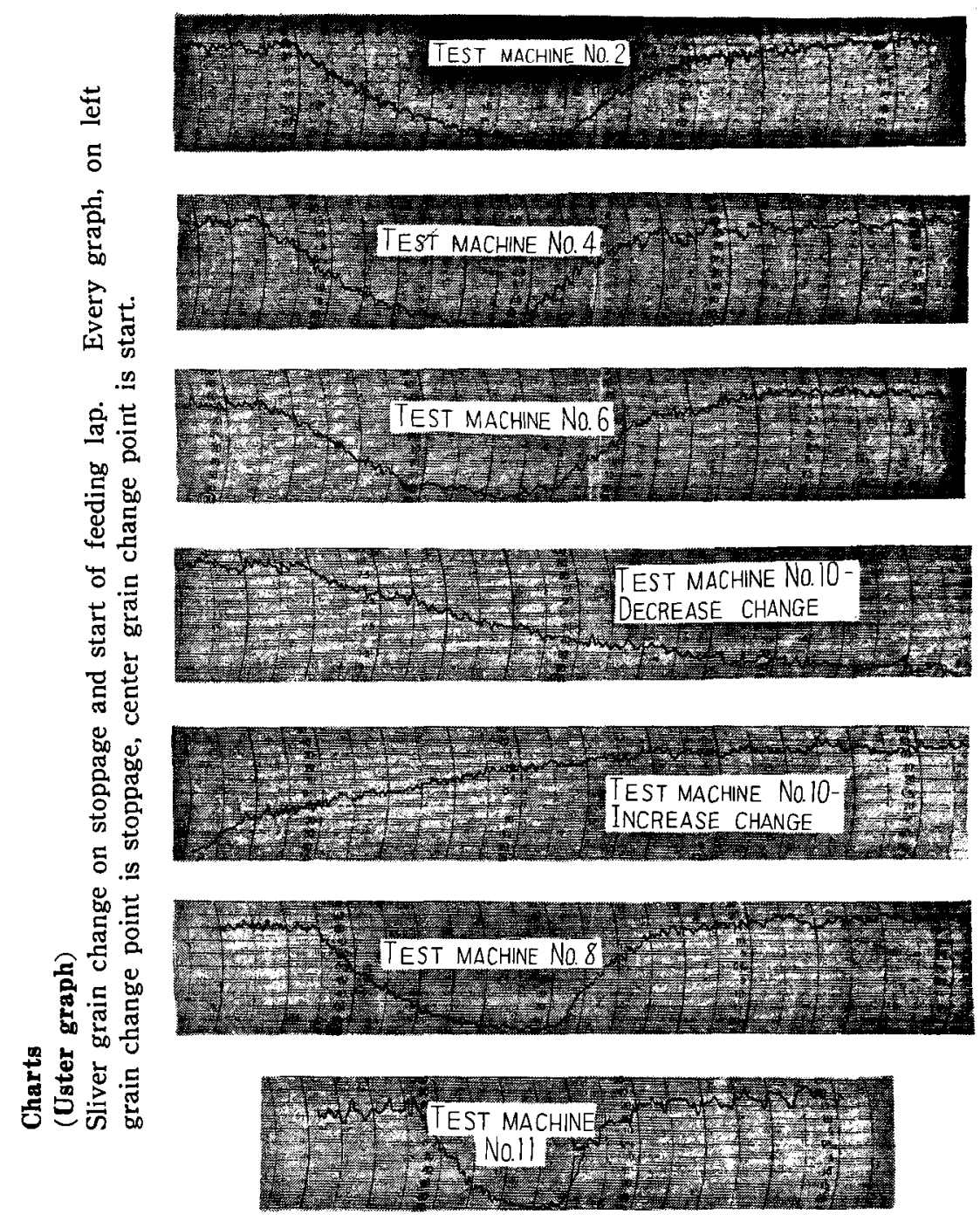

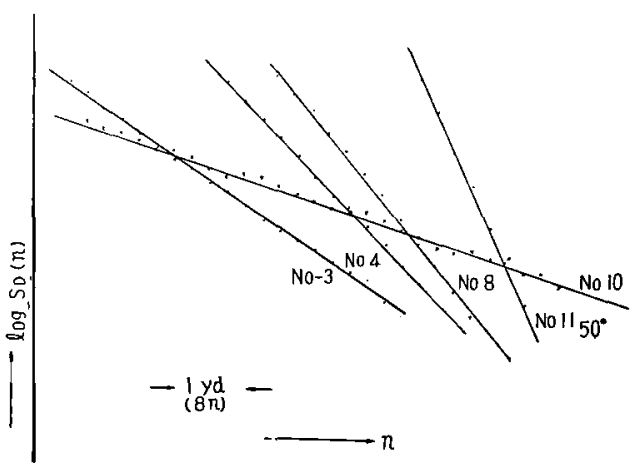

Fig.6 Experimental value of $\log S_{D}(n)$ on decrease $n:$ Cyl r.p.m. (lyd-8n) to card slivers of over 30 grains/ 6 yards, if the rate of transfer is constant. As regards the roller card, the variation resembles to that of ordinary type, if the rate of transfer is assumed to be the so-called superficial rate of transfer.

It can be concluded, then, that, under certain machine conditions, the rate of transfer is constant irrespective of the fiber quantity on the cylinder. The fiber quantity tranferred from the cylinder to the doffer is proportionate to the fiber quantity on the cylinder.

Table 3 shows the rates of transfer in four or five tests, each value given being the mean value. When sliver grains change with the stoppage of lap- 
Table 3 Rate of transfer and fiber quantity on cylinder

\begin{tabular}{|c|c|c|c|c|}
\hline \multirow{2}{*}{$\begin{array}{c}\text { Test } \\
\text { machine } \\
\text { No. }\end{array}$} & \multicolumn{2}{|c|}{$\begin{array}{l}2 \mathrm{D} \times 57 \mathrm{~mm}(25 \%) \\
3 \mathrm{D} \times 57 \mathrm{~mm}(75 \%)\end{array}$} & \multicolumn{2}{|c|}{$30 \times 76 \mathrm{~mm}(100 \%)$} \\
\hline & $\begin{array}{c}\text { Rate of } \\
\text { transfer } \\
(\%)\end{array}$ & $\begin{array}{c}\text { Fiber } \\
\text { quantity } \\
\text { (grain) }\end{array}$ & $\begin{array}{c}\text { Rate of } \\
\text { transfer } \\
(\%)\end{array}$ & $\begin{array}{c}\text { Fiber } \\
\text { quantity } \\
\text { (grain) }\end{array}$ \\
\hline 1 & 6.3 & 95.3 & & \\
\hline 2 & 7.3 & 82.2 & & \\
\hline 3 & 6.5 & 92.4 & & \\
\hline 4 & 8.9 & 67.5 & 9.87 & 62.7 \\
\hline 5 & 9.1 & 66.0 & & \\
\hline 6 & 8.8 & 68.2 & & \\
\hline 7 & 9.1 & 66.0 & & \\
\hline 8 & 9.7 & 62.1 & 10.4 & 57.5 \\
\hline 9 & 11.3 & 53.2 & & \\
\hline 10 & 3.12 & 192 & 4.28 & 140 \\
\hline $\begin{array}{ll}11 & 50 \\
60\end{array}$ & $\begin{array}{l}17.1 \\
13.2\end{array}$ & $\begin{array}{l}35.1 \\
45.5\end{array}$ & & \\
\hline
\end{tabular}

feeding, $1-P$ is about $7 \%$ on fillet clothing, compared with about $9 \%$ on metallic clothing. $1-P$ is as much as $9.7 \%$ on tester No. 8 which has a working angle of doffer metallic wire of $69^{\circ}$ The tester No. 11 , showing $13.2 \%$ for $60^{\circ}$ and $17.1 \%$ for $50^{\circ}$ Thus, the smaller the working angle of doffer metallic wire, the larger the rate of transfer. To get the same effect, lower wire as of the tester No. 9 gives good promise.

The extraordinarily small rate $3.12 \%$ on tester No. 10 should be taken as the so-called superficial rate, because even after the stoppage of lap-feeding, there is a supply of fibers from the woker part to the cylinder.

Chances are that a higher rate of transfer makes slivers uneven. To overcome this, trouble we recommend attaching one or two pairs of woker-stripper rollers to the cylinder so that the so-called superficial rate of transfer may be reduced without changing the fiber quantity on the cylinder. The rate of transfer conceivably with the kind fiber used. Use first fibers of $2.66 \mathrm{D} . \times 57 \mathrm{~mm}$ in cut length then change it to $3 \mathrm{D} . \times 76 \mathrm{~mm}$ increases $1-P$ by $1 \%$. In other words, $1-P$ can be more easily increased and the fiber quantity on the cylinder reduced by using fibers of a thick denier and a long cut length.

The fiber quantity on the cylinder obtained from fiber quantity $1-P$, which does not contain sinking fibers in fillet clothing is as given in Table $3 . \quad$ The quantity is remarkably small. Fibers sinking in the cylinder of ordinary fillet clothing amounts to more than 1,000 grains about two hours after vacu. um stripping. On the other hand, the quantity of fibers attached to the top during operation is about 400 grains on fillet clothing and 250 grains on metallic clothing. Therefore, the fiber distribution on fllet clothing during operation is queezed so to speak, between 1,000 grain flbers sinking in the cylinder 400 grain, nep-infested flbers sticking to the top, with the result that only 90 grain fibers receive carding action.

Since there are no sinking fibers in the cylinder in metallic clothing, carding action bears lesser loading. This means lesser fiber on cylinder. Hence wire-tooth spacing smaller, which is offset by the fact that there is no sinking fiber on cylinder. Consequently more of wire-tooth spacing. It assures of efficient action of carding.

To sum up, it is possible to increase production, with less time for carding, by increasing the rate of transfer on metallic clothing and reducing the fiber quantity on the cylinder at the same time.

The fiber quantity on the cylinder and $P$ were measured by theoretical formulas. $1-P$, of course, is concerned with sliver produced. This accounts for the comparatively greater value of the rate of transfer than when fibers on the cylinder do not include sinking fiber or waste fibers.

Our experiments have raised new questions. One of them is : Why are there sinking fiber in fillet clothing and none in metallic clothing ? The question await looking into.

The last but not the least is the clarification of the concept of the rate of transfer. And it is constant under a certain conditions. This finding helps a great deal to study the relation between lap feeding and sliver producing under actual variation of feeding fiber. 